\title{
E-Learning Use Patterns in the Workplace - Web Logs from Interaction with a Web Based Lecture
}

\author{
http://dx.doi.org/10.3991/ijac.v5i4.2209 \\ Christian Ostlund \\ University West, Trollhattan, Sweden
}

\begin{abstract}
When designing for e-learning the objective is to design for learning i.e. the technology supporting the learning activity should aid and support the learning process and be an arena where learning is likely to occur. To obtain this when designing e-learning for the workplace the author argue that it is important to have knowledge on how users actually access and use e-learning systems. In order to gain this knowledge web logs from a web lecture developed for a Scandinavian public body has been analyzed. During a period of two and a half months 15 learners visited the web lecture 74 times. The web lecture consisted of streaming video with exercises and additional links to resources on the WWW to provide an opportunity to investigate the topic from multiple perspectives. The web lecture took approximately one hour to finish. Using web usage mining for the analysis seven groups or interaction patterns emerged: peaking, one go, partial order, partial unordered, single module, mixed modules, non-video modules. Furthermore the web logs paint a picture of the learning activities being interrupted. This suggests that modules needs to be fine-grained (e.g. less than 8 minutes per video clip) so learners' do not need to waste time having to watch parts of a video clip while waiting for the part of interest to appear or having to fast forward. A clear and logical structure is also important to help the learner find their way back accurately and fast.
\end{abstract}

Index Terms-Web logs, Design science research, Web lecture application, Work-integrated e-learning.

\section{INTRODUCTION}

When the main objective of design is that people are supposed to learn something, the first thing to remember is that one cannot design learning - only design for learning [1], meaning that the design work should result in an arena or a space where learning (that corresponds to the intentions of the designer) is likely to occur. When designing for e-learning the designer needs to address both the element of instructional (pedagogical) design which frames a series of activities where the learner(s) should engage individually and/or together with peers and tutors, and the element of systems design that should provide the tools, functionalities and virtual spaces where the learning activities can be enacted. This is sometimes referred to as a conflict between pedagogical pull and technological push (Nuldén, 1999), but is probably better treated as a duality where the goal is to integrate the two.

When discussing learning in the workplace a distinction is often made between informal learning e.g. when colleagues tell stories about and discuss their daily practice (e.g. [2] and more formal (scholastic) learning e.g. attending a course in a subject of relevance for the work [3]. Workplace learning is of course a huge area that encompasses everything from learning how to start the coffee machine or logging on to the company intranet to learning strategic management skills or doing research for product development.

The challenges and costs that arrive with coordinating nationwide competence development initiatives have prompted large organizations to seek effective and cost efficient alternatives to local and often un-coordinated solutions. Work-integrated e-learning is a popular alternative because of the potential advantages such as independence of place; substantial cost savings due to the elimination of travel expenses; timely access to information; greater flexibility in the workplace and methods that can increase learners' interest in the subject at hand [4].

Research within a wide range of academic fields such as educational technology, asynchronous learning networks (ALN), computer support for collaborative learning (CSCL), and computer-aided instruction (CAI) has over the years provided valuable contributions to the understanding of the conditions for e-learning design. However, most of the work is based on empirical data collected from school settings dominated by Higher Education and are in most cases connected to small scalepilot projects. Furthermore, the implications for design that can be derived from this research is, with a few notable exceptions [5-8], not presented in a format that could qualify as a design theory.

This lack of established theories and frameworks for the design for formal work-integrated e-learning needs to be addressed and there are good reasons to assume that that scholastic learning at the workplace differs with respect to a number of aspects compared to learning in school settings. Firstly due to the fact that is about learning in work at the workplace as oppose to learning for (future) work at school [9], but also because the learners' resources in terms of time, attention and engagement constantly has to compete with all the other commitments of everyday work. However most attempts to differentiate between various kinds of workplace e-learning tend to focus more on the technology than on the objective and conditions of the learning. For instance, Hendersson [10] makes a distinction between synchronous learning, selfdirected learning and asynchronous (collaborative) learning.

This paper reports from the initial steps of formulating a prescriptive design theory to support the development of scholastic/formal work-integrated e-learning systems. The setting is within the county administration. The county administration has initiated a corporate university called the academy of the county administration, aiming at delivering courses and training for all employees across 


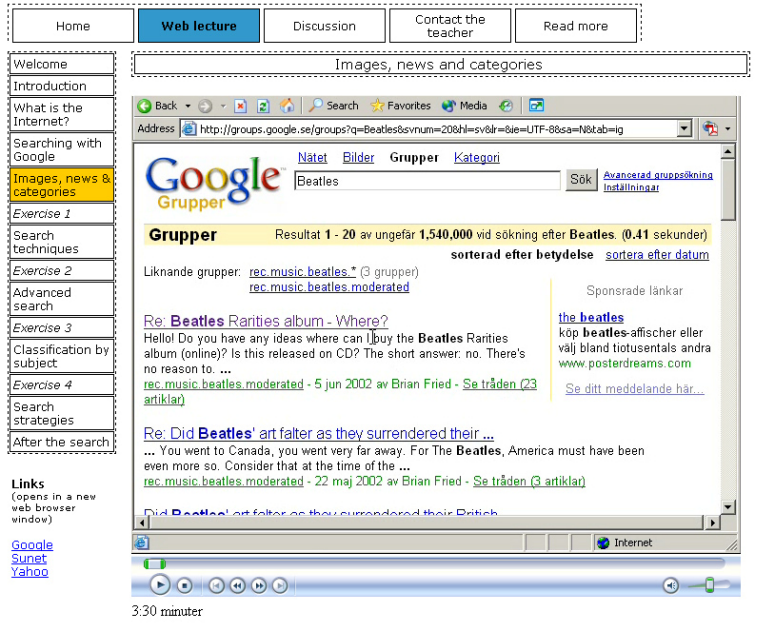

Figure 1. A narrated screen capture exemplifying a search in Google

the nation. For this purpose an application for delivering web lectures was designed using the design research cycle by Vaishnavi and Kuechler [11]. Furthermore; the design work was guided by the authentic learning framework by Herrington and Herrington [6], hence the research question of this paper is:

When and how do learners interact with formal elearning systems in a work context?

\section{THE WEB LECTURE APPLICATION VERSION 1}

The first version of the web lecture application (WLA) consisted of streamed videos, a discussion board, information on how to contact the teacher and a read more section, a list of links with additional resources on how to search the World Wide Web (WWW). Under the home section the users are informed about the overall purpose and content of the WLA and that the time to finish the web lecture is estimated to approximately one hour.

The video part of the WLA under web lecture consists of streamed video (see figure 1). The videos are either narrated slides or narrated screen captures of for example a search for Beatles using the Google category search. The video lecture consists of an introduction, search techniques and search strategies with 4 assignments in between. In all there are nine modules ranging from 3 to 8 minutes each.

In the discussion section the users where encouraged to post difficult searches, successful or not, that they have had and the web lecture application in general in a debate forum. Under the teacher section information about the teachers e-mail where available and a text stating that they were welcome to contact the teacher about anything related to the web lecture application. The read more section had links to resources on the WWW about searching on the WWW was divided into two parts, one with links to Swedish resources and one with links to English resources.

\section{WEB LECTURE APPLICATION VERSION 2}

To address the shortcomings of the unused debate board an assessing assignment was developed, giving the teacher/instructor a more active role. In order to further motivate the completion of the assignment rendered in a certificate. The assessment is two folded one part where the employees receive feedback from their peers and one part where they receive feedback from an expert. For the assessment the employee describes a search they have done relating to their work practice on which they get expert feedback. They are also to comment on a search description handed in by another peer to actively reflect upon and apply the knowledge they have gained.

\section{WEB LOGS}

The WL is a hypertext or hypermedia system created with hypertext markup language (html). Hypertext is often defined as non-sequential writing and reading of information $[12,13]$ although it is still possible to make a strictly linear hypertext document by only linking to the nodes next in the intended order. Linear hypertext documents are useful when the information that is being presented by the system is meaningful to the users only when received in a specific order. For some educational and instructional purposes a step-by-step procedure of this kind is very useful. Although the WL of our case is intended to be followed in a specific order a linear structure with options [14] was chosen, meaning it is structured in a certain way, but all modules in the structure are reachable at all times and the user can choose to see the modules in any order. This gives the users the choice to either take the modules in the suggested order (in one go or at two or more occasions), skip certain modules or take the modules in an exploring unordered way. The users also have the opportunity to go back and re-visit certain modules directly. The path history or clickstream of how the users navigate through the WL is stored in log files on a server.

To analyze the users' clickstream the process of web usage mining (WUM), often used in the electronic commerce area, was used to extract the navigation behavior patterns. WUM consist of the core phases; data pre-processing, pattern discovery and pattern analysis [15]. The data pre-processing phase can be divided into 7 sub processes; data cleaning, data filtering, user identification, session identification, path completion, data enrichment and transaction identification [16]. The task of data cleaning aims at removing irrelevant records like accessing a stylesheet file or the loading of irrelevant pictures such a logos. For the purpose of this paper entries like from files like soka.css and hv_logo_se.jpg were edited out. Left in the log file where e.g:

2007-03-15 08:49:07 GET /Attsoka/02.html XX.XXX.XX.95

2007-03-15 08:58:20 GET /Attsoka/03.html - XX.XX.XX.95

\section{7-03-15 09:04:46 GET /Attsoka/04a.html - - XX.XX.XX.95}

For the sake of anonymity the ip-numbers at the end (XX.XX.XX.95) are X:ed out in the above example. In the data filtering phase [16] a subset of data relevant for the mining objective is extracted, e.g. selecting a set of records from a certain activity or period. Since the studies in this paper had clear test periods, the records from the test periods of the WLAs were chosen. When it came to user identification the use of proxies at some of the workplaces in the study made it difficult to distinguish unique users in some cases. Normally when users have the same IP address unique users can sometimes be identified if they use different operating systems or browsers [15] since this also is registered. At the workplace in this study 
the employees' computers were batch installed and therefore had the same operating system and browser. Despite this multiple sessions can be traced to a unique user with high probability if e.g. pages $01 . h t m l$ through 05.html is accessed and later the same day pages 06.html through 09.html is accessed. Overall the issue of identifying unique user are not essential for this study since it deemed of little value in this relatively small web site that make up the WLA to be able to say that $50 \%$ of all users who accessed the first video module also visited the read more module.

The task of session identification consists of grouping the users' visits into session units [16]. The web server that hosted the WLA had a session timeout set to 30 minutes which means that if a user does not change page or refresh the page they are currently visiting, the server stops logging after 30 minutes as if the user left the web site. The WLA was made up by html frames in the sense that the main menu (see Home, Web lecture, Discussion and so on in figure 1) is put in a separate frame and the different modules like Web lecture is loaded in a frame below the main menu. This way the menu is always present at the top, but it also means the URL does not change when the user clicks on a link within the WLA. The consequence of this is that a user who is e.g. looking at the video module that is lasting approximately 50 minutes in one go, will be logged as two sessions. The solution for this is looking at all sessions that are 30 minutes and see if the next session matches the previous one identity and pattern wise. This only occurred twice in the logs. Another issue when identifying unique user sessions, addressed in the path completion phase [16], is to determine whether or not there are any user accesses that are not recorded in the log file, e.g. if a user leaves the site or if the user is backtracking and accessing pages from a cache instead of the web server. The WLA had external links in the read more module and links to Google, Sunet and Yahoo in the streamed video module. Since the users' are encouraged to visit Google, Sunet and Yahoo in the different exercises, the WLA logs will be examined where these entries are to see if too sessions in the web log in reality are one session where the user leaves the site to test what they have learned.

In the data enrichment phase [16] the log entries are enriched with data from e.g. user profiles. Because of the difficulties with user identification mentioned above the only enrichment of data that was done was that of geographic data. The final task of the data pre-processing phase is transaction identification [16] where sessions are grouped into smaller and more significant page groups. In the transaction identification phase seven groups or interaction patterns emerged:

In the pilot study the frequency of the patterns where distributed as shown in figure 2 .

Figure 3 represents a chart of the video module only. In this chart the $18 \%$ from the mixed module category is spread out on the partial order, partial unordered single module, and one go categories. E.g. out of all the mixed module user patterns, 5 of them where visits in the partial order category with additional visits on the one or more of the non-video pages. These 5 visits are incorporated into the partial order category.

In the $2^{\text {nd }}$ study the frequency of the interaction patterns where distributed as shown in figure 4.
The interaction patterns from the second version with the video interactions only parts (see figure 5).

Comparing visits by hour of day (figures 6 and 7), two peaking periods are revealed in the morning and around lunch time. The lunch hour peak shows that most visits are made before, during or after lunch. There is a significant decrease during the afternoon and in the evening.

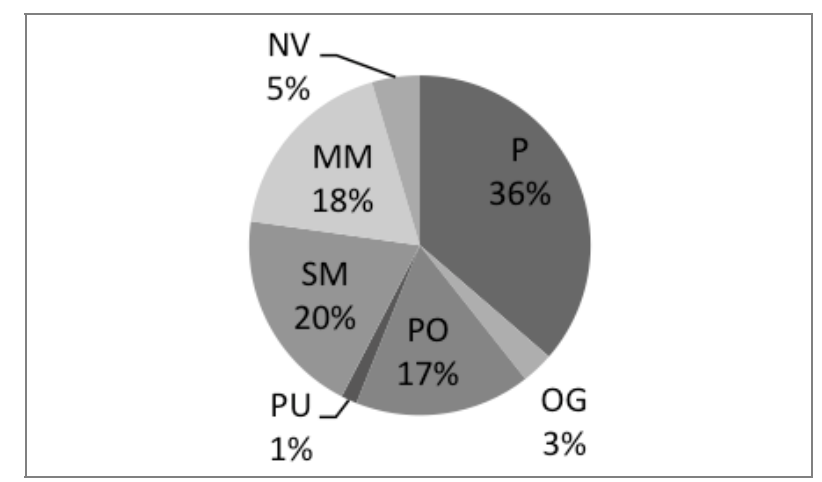

Figure 2. Chart with all interaction patterns 1st version

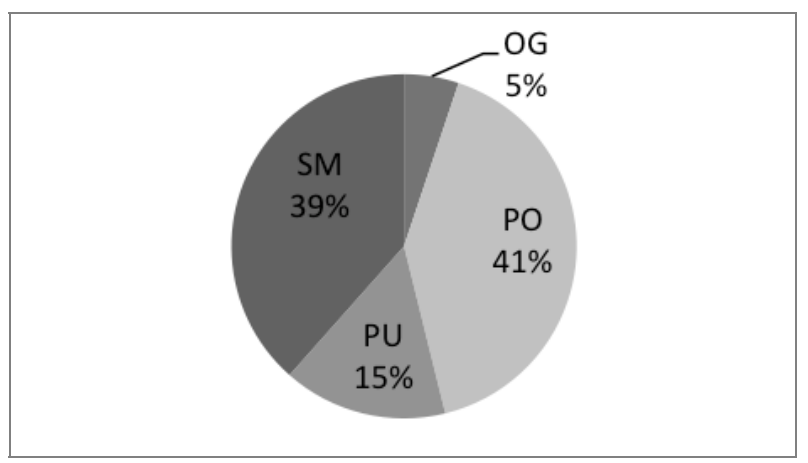

Figure 3. Chart with video interaction patterns 1st version

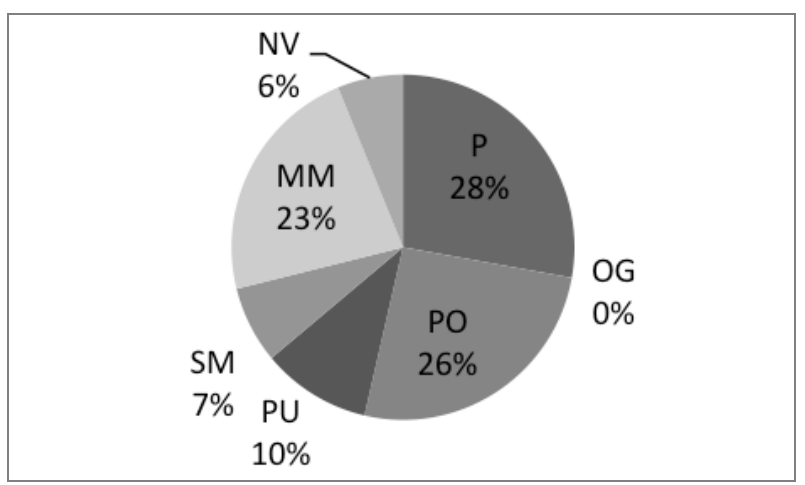

Figure 4. Chart all interaction patterns 2nd version

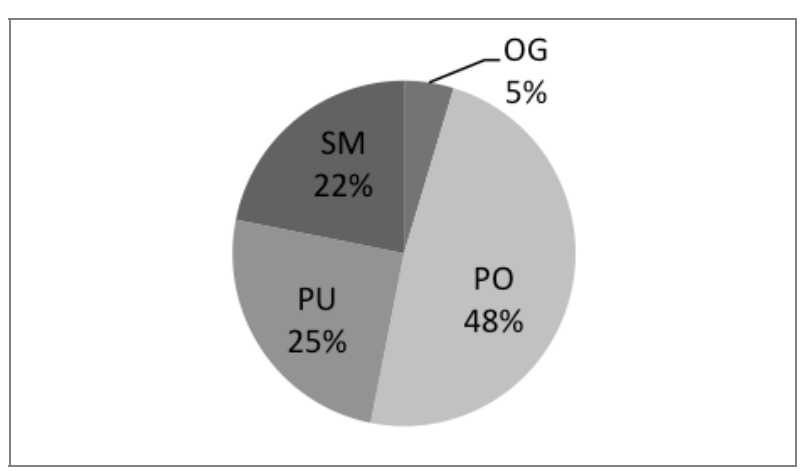

Figure 5. Chart with video interaction patterns 2nd version 


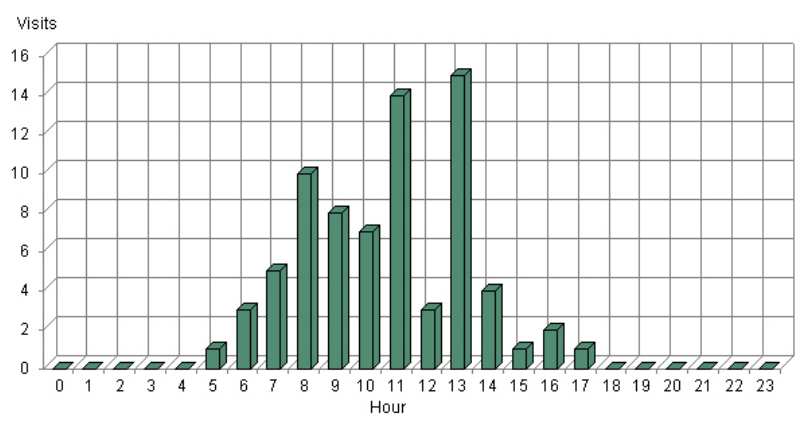

Figure 6. Visits by hour of day from version 1

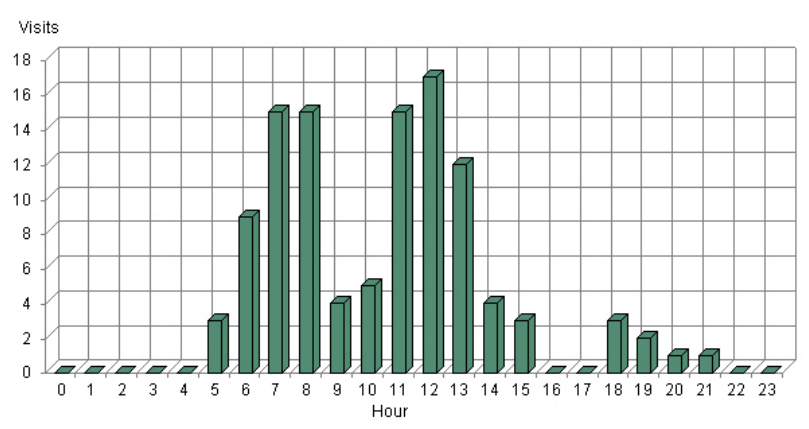

Figure 7. Visits by hour of day from version 2

\section{INTERVIEWS}

Out of a total of twenty participants, nine where interviewed. The semi-structured interviews where done over the phone since the interviewees where spread across the western of Sweden. The county administration also has a long tradition of phone meetings, so interviews over the phone were deemed to be quite natural for them. The interviews were recorded with their permission and stored electronically as mp3-files. They were later transcribed with the help of the transcription software Express Scribe for playback and pausing and stored in Word. Later they were coded using ATLAS.ti. The interviews evolved around the employees' experiences with the WLA and what affected that experience, e.g. how did the work tasks affect the interaction with the WLA? This resulted in a semi-structured interview guide where the following sub categories are of relevance for this paper:

1. Work context

2. Computer experience and previous interaction with e-learning systems

3. Interaction with system, how they took part of the web lecture.

4. Interaction with peers

5. Interaction with system

The employees also pointed out the importance of easily being able to continue the web lecture after a break or an interruption. Another aspect that came out of the interview process was the fact that some needed a push to get started. When some of the employees' where contacted for the interview they said that they have not had time to do the web lecture yet although they would very much like to. They asked us if we could get back to them in a couple of months and when we later contacted them, they had all finished the web lecture. One interviewee expressed a need for some type of structure:
TABLE I

INTERACTION WITH THE SYSTEM

\begin{tabular}{|l|c|}
\hline \multicolumn{1}{|c|}{ Code } & Occurrences \\
\hline Haven't tried e-learning before & 6 \\
\hline Considers going back to the WL in future & 3 \\
\hline Controlled when they took part of the WL & 1 \\
\hline Did not feel the need for a schedule & 6 \\
\hline Split the web lecture in 2 or more times & 6 \\
\hline Work tasks controlled when they did the WL & 7 \\
\hline $\begin{array}{l}\text { Didn't feel need to interact with other } \\
\text { participating in the WL }\end{array}$ & \\
\hline
\end{tabular}

"One advantage with the local courses we've had before, for the most parts it is someone who comes to us and visits the different offices, then there is a time and a place set aside for the occasion. Then you book it and it gets done. These types [e-learning like "searching the WWW". Authors note] when it is up to yourself, you need to have discipline to get it done. Often it is like: Oh, I don't have time for this now, it will have to wait. It just never gets done."

The lack of time was also a factor in their interaction with the system, when asked if they did the exercises two responded:

"Yes, some of them but not all of them.

So you didn't feel the need to...

No, some were quite obvious and some I didn't do due to lack of time really."

"Yes, I did some but at the end I weren't as ambitious because... well it was a bit more extensive."

The debate board was still unused and when asked about collaboration with other learners they still felt no need for that although some of the interviewees had discussed the content with local colleagues or members of their family. They expressed that it made more sense to discuss with their local colleagues, even if the colleagues did not participate in the web lecture:

"Because it is more spontaneous at the coffee break and yes, sometimes when I visited someone. I've even made suggestions during meetings.”

In one case two colleagues in the same department participated in the course, and in that case it made even more sense to discuss it face to face.

\section{DISCUSSION}

Adapting authentic learning [6] to the conditions of formal work-integrated e-learning calls for a simplification of the framework. Articulation, collaboration coaching \& scaffolding and integrated assessment becomes peripheral when developing formal work-integrated e-learning systems, whereas authentic context, authentic activities, expert performance, multiple perspectives and reflection become more central [17]. Aside from this theory of learning, the empirical data from 
the interaction with the WLA gives indications for a theory of use as well.

\section{A. Fine-granularity}

The employees' in the study had ordinary office jobs with normal working hours. The morning peak could indicate that the learners' more or less starts the day off with the web lecture before the workload sets in. The peak around lunch hour could also indicate that workplace learners' utilizes the natural break for lunch to engage in learning activities. This paints a picture of work tasks controlling when learning activities takes place. There is no peak in the afternoon, rather a decrease in the afternoon, so it would seem that they go to the web lecture application only in the non-busy periods when they must remain on the job afterwards.

This suggests that the modules that make up the web lecture needs to be fine-grained, i.e. short video clips so the learners' do not need to waste time having to watch parts of a video clip while waiting for the part of interest or having to fast forward. A clear and logical structure is also important to help the learner find their way back accurately and fast. The need for this is also evident in the surveys and the interviews. The survey shows that $40 \%$ of the learners have returned and re-watched parts of the web lecture and $70 \%$ divided the web lecture into two or more sessions. In the interviews six out of nine said they considered going back to the web lecture in the future and six got interrupted by work while doing the web lecture.

\section{B. Peer interaction}

The data also reveals that the employees' did not fell a need for interacting with other, previously unknown who also attended the web lecture. They would rather interact with their peers who did not attend the web lecture but with whom they shared a practice.

\section{Attention}

Another aspect that came out of the interview process was the fact that some needed attention or a push to get started. When some of the employees' where contacted for the interview they said that they have not had time to do the web lecture yet although they would very much like to. They asked us if we could get back to them in a couple of months and when we later contacted them, they had all finished the web lecture. The problem of "not getting it done" arriving with flexibility was also expressed in the interviews.

\section{REFERENCES}

[1] Wenger, E., Communities of practice : learning, meaning, and identity. Learning in doing, 99-1331144-61998, Cambridge: Cambridge University Press.
[2] Orr, J.E., Talking about machines1996, NY: ILR Press Ithaca.

[3] Coleman, G., et al., Multimedia training in the pig industry. Computers \& Education, 2001. 37(3-4): p. 257-271. http://dx.doi.org/10.1016/S0360-1315(01)00051-3

[4] Park, J.H. and T. Wentling, Factors associated with transfer of training in workplace e-learning. JOURNAL OF WORKPLACE LEARNING, 2007. 19(5): p. 311. http://dx.doi.org/10.1108/ 13665620710757860

[5] Hardless, C., Designing competence development systems, in Gothenburg studies in informatics, 1400-741X; 322005, Department of Informatics, Göteborg University: Göteborg.

[6] Herrington, A. and J. Herrington, Authentic learning environments in higher education.2006, Hershey: PA: Information Science Publishing.

[7] Hrastinski, S., Participating in synchronous online education, in Lund studies in informatics (Lund 2002), 1651-1816 ; 62007, Department of Informatics, Lund University: Lund.

[8] Hung, D.W.L. and D. Chen, Situated Cognition, Vygotskian Thought and Learning from the Communities of Practice Perspective: Implications for the Design of Web-Based ELearning. Educational Media International, 2001. 38(1): p. 3-12.

[9] Lundin, J., Talking about work. Designing information technology for learning in interaction. 2006.

[10] Henderson, A.J., The E-Learning Question and Answer Book: A Survival Guide for Trainers and Business Managers2002: AMACOM Div American Mgmt Assn.

[11] Vaishnavi, V.K. and W. Kuechler Design Science Research Methods and Patterns: Innovating Information and Communication Technology2007: Auerbach Pub.

[12] Chen, S.Y. and N.J. Ford, Modelling user navigation behaviours in a hyper-media-based learning system: An individual differences approach. Knowledge organization, 1998. 25(3): p. 67-78.

[13] Nielsen, J., Multimedia and hypertext : the Internet and beyond1995, Boston ;: AP Professional.

[14] Powell, T.A., Web design : the complete reference2000, Berkeley, Calif. ;: Osborne/MacGraw-Hill.

[15] Cooley, R., B. Mobasher, and J. Srivastava. Web mining: Information and pattern discovery on the world wide web. 1997.

[16] Marquardt, C.G., K. Becker, and D.D. Ruiz. A pre-processing tool for Web usage mining in the distance education domain. in Database Engineering and Applications Symposium, 2004. IDEAS '04. Proceedings. International. 2004.

[17] Ostlund, C. and L. Svensson. Web Lectures for Authentic Workplace e-learning. in International conference on e-learning in the workplace. 2009. Colombia University, NY, USA.

\section{AUTHOR}

Christian Ostlund is with the Department of economics and IT at the University West, 46186 Trollhattan, Sweden. He is also with the Department of Informatics as a PhD-student at the Copenhagen Business School in Denmark (e-mail: christian.ostlund@hv.se).

Received 01 April 2012. Published as resubmitted by the author 14 November 2012. 